\title{
ASPECTOS BIOÉTICOS DA VACINAÇÃO EM MASSA NO BRASIL
}

\author{
Andreia Souza de Jesus ${ }^{1}$, Luanna Rodrigues de Jesus ${ }^{1}$, Vanessa de Oliveira Vieira ${ }^{1}$, Edite Lago da Silva \\ Sena ${ }^{1}$, Rita Narriman Silva de Oliveira Boery ${ }^{1}$, Sérgio Donha Yarid ${ }^{1}$
}

Resumo: A vacinação em massa consiste na realização coletiva da prática vacinal, utilizando como estratégias as campanhas, mutirōes e bloqueios, realizadas sem considerar os riscos epidêmicos e outras questóes, implicando na perda da autonomia e vulnerabilidade dos indivíduos. Este estudo tem como objetivo realizar uma discussão referentes à prática da vacinação em massa sob a ótica da Bioética Principialista considerado o papel do Estado e os aspectos culturais relacionados a essa prática. Trata-se de uma revisão de literatura com recorte temporal de 1999 a 2013 em periódicos nacionais. Concluiu-se que ocorre desvalorização dos princípios éticos relacionados a autonomia, não-maleficência, beneficência e justiça, bem como uma desconsideraçáo dos aspectos culturais dos vacinados por parte do Estado e dos profissionais de saúde. O Estado ainda é hoje o maior incentivador das práticas de vacinação em massa por serem medidas mais simples de prevenção das doenças uma vez que ainda existe uma precariedade nas infraestruturas sanitárias no país, no entanto, em contra partida, seria necessário estimular a conscientização da população e o aperfeiçoamento do controle sanitário que seriam a longo prazo opçóes necessárias para que em certos lugares se descontinuassem essa prática.

Palavra-chave: bioética, vacinação em massa, características culturais, economia da saúde

\section{Bioethic aspects of mass vaccination in Brazil}

\begin{abstract}
Mass vaccination is the collective achievement of immunization practice, using strategies such as campaigns, task forces and locks, made without considering the epidemic risks and other issues, resulting in the loss of autonomy and vulnerability of individuals. This study aims to conduct a discussion regarding the practice of mass vaccination from the perspective of bioethics principialist considered the role of the state and the cultural aspects of this practice. This is a review of literature with time frame 1999-2013 in national journals. It was concluded that occurs devaluation of ethical principles related to autonomy, non-maleficence, beneficence and justice, as well as a disregard of cultural aspects of vaccinees by the state and health professionals. The state is still the biggest supporter of mass vaccination practices by being simpler measures of disease prevention since there is still a precarious health infrastructure in the country, however, although, it would be necessary to stimulate public awareness and the improvement of sanitary control that would be long-term options needed for certain places if they stopped this practice.
\end{abstract}

Key words: bioethics, mass vaccination, cultural characterirtics, health economics

Aspectos bioéticos de la vacunación en masa en Brasil

Resumen: La vacunación masiva es un logro colectivo de la práctica de la inmunización, utilizando estrategias como campañas, grupos de trabajo y aislamientos realizados, sin considerar los riesgos de epidemias y otras cuestiones, lo que resulta en la pérdida de la autonomía y la vulnerabilidad de los individuos. Este estudio tiene como objetivo llevar a cabo una discusión sobre la práctica de vacunación masiva desde la perspectiva de la bioética principialista, considerado el papel del Estado y los aspectos culturales de esta práctica. Se trata de una revisión de la literatura entre los años 1999 y 2013 en revistas brasileras. Se concluyó que hay una devaluación de principios éticos relacionados con la autonomía, no maleficencia, beneficencia y justicia, y una falta de respeto a los aspectos culturales de los vacunados por parte de los funcionarios de salud pública. El Estado sigue siendo el mayor encargado del mantenimiento de las prácticas de vacunación masiva, con medidas simples para prevenir la enfermedad, aunque todavía hay una deficiente infraestructura sanitaria en el país; sin embargo, sería necesario aumentar la conciencia pública y mejorar el control sanitario, y definir las medidas a largo plazo en ciertos lugares en caso de cese esta práctica.

Palabras clave: bioética, la vacunación masiva,, economía de la salud culturales

\footnotetext{
${ }^{1}$ Universidade Estadual do Sudoeste da Bahia, Brasil

Correspondencia: andreiasouzad@yahoo.com.br
} 


\section{Introdução}

As vacinas são utilizadas há muitos anos em todo o mundo no controle e prevenção de doenças infecciosas, sendo consideradas como tecnologias efetivas e de menor custo $(1,2)$.

As primeiras vacinações no Brasil foram realizadas em 1804 e desde então, foram utilizadas diversas estratégias para a sua realização como campanhas, varreduras, rotina e bloqueios, tendo erradicado a febre amarela urbana em 1942, a varíola em 1973 e a poliomielite em 1989. Mais recentemente as estratégias de vacinação também foram responsáveis por controlar o sarampo, o tétano neonatal, as formas graves da tuberculose, a difteria, o tétano acidental e a coqueluche, dentre outras(3).

Ao longo dos anos, novos imunobiológicos foram introduzidos à rotina de vacinaçáo, completando o que compóe hoje o calendário básico disponível no Sistema Único de Saúde (SUS). A introdução da vacina papilomavírus humano (HPV) quadrivalente foi a mais recente novidade do Programa Nacional de Imunização (PNI), que tem como alvo as adolescentes com faixa etária de 11 a 13 anos de idade da rede pública e tem como objetivo reforçar as atuais ações de prevenção do câncer do colo do útero(4).

Vale destacar que o crescimento da população traz implicaçóes diretas como o aumento do número de doses de vacinas aplicadas e, consequentemente, a maior probabilidade de eventos adversos relacionados com o procedimento. Esse fato tem chamado atenção da população, a qual tem demonstrado maior preocupação com esses eventos do que com a prevenção induzida pelas vacinas propriamente dita(5).

Outro fato interessante é a quantidade dos eventos adversos relacionados a falhas no processo de vacinação, conhecido como erros programáticos. Os erros mais comumente mencionados têm sido, falta de lavagem das mãos, diluição incorreta do imunobiológico, local incorreto de administração, injeção rápida do conteúdo vacinal, dentre outros(5).

Desse modo, o sucesso dos programas de vacinação tem sido comprometido, pois além de es- tarem interferindo na aceitação da vacinação, tem diminuído o seu alto padrão de segurança. Somado a isso, o fato das vacinas serem administradas compulsoriamente em crianças saudáveis sem considerar os riscos epidêmicos e outras questôes relacionadas tem prejudicado a autonomia e vulnerabilidade dessa população(1).

Sabe-se que a descoberta das vacinas tem sua importância na história da ética médica, porém é importante refletir sobre a moral da vacinação, considerando situaçóes como a imprevisibilidade de seu efeito no organismo humano a longo prazo, a emergência de declaraçóes universais de proteção aos direitos humanos, a modificação da relação médico-paciente, o pluralismo moral contemporâneo e, além disso, o conflito de interesse individual e coletivo(1).

Outro fato importante é que o foco de atenção quando se fala em vacinação, ainda se concentra especialmente em manter os altos índices de cobertura vacinal. Nessa perspectiva, continua em discussão o conflito ético entre autonomia individual e o bem coletivo(1).

\section{Vacina, autonomia e vulnerabilidade: uma visão da bioética principialista}

Ao longo dos anos, as diversas inovaçóes da área da saúde fizeram surgir algumas divergências, no que se refere ás questóes sociais, éticas e jurídicas. $\mathrm{Na}$ busca por atender esses problemas éticos surge a bioética principialista, que tem como foco principal discutir as relaçóes entre a medicina, a ética e o direito(6).

O principialismo é uma corrente que tem se difundido atualmente em todo mundo, baseada nos seus quatro princípios: autonomia, beneficência, não maleficência e justiça. Dessa forma, busca resolver questôes surgidas nas sociedades contemporâneas caracterizadas pelo pluralismo moral, de modo a mediar diferentes posiçōes morais e éticas, resultando não em resoluçôes definitivas dos problemas enfrentados, mas em acordos pragmáticos(7).

Na saúde pública existe hoje um conflito acentuado entre os interesses individuais e coletivos, o que tem resultado, na maioria das vezes, na vio- 
lação da autonomia e vulnerabilidade dos sujeitos em sua individualidade, um exemplo disso é a vacinação(1).

Muitos países têm leis mandatórias quanto á utilização da vacina, no Brasil é de caráter obrigatório, exceto para às pessoas que tenham indicação médica. Essa obrigatoriedade é regulamentada desde 1975, pela lei No 6.259, que dispóe sobre a organização das ações de Vigilância Epidemiológica, incluindo o Programa Nacional de Imunização $(8,9)$.

$\mathrm{O}$ artigo $3^{\circ}$ dessa lei discrimina sobre o caráter obrigatório das vacinaçóes, definindo enquanto práticas sistemáticas e gratuitas a serem realizadas pelos órgãos e entidades públicas, bem como pelas entidades privadas, subvencionadas pelos Governos Federal, Estaduais e Municipais, em todo o território nacional(9).

Fica explicito que o princípio da autonomia, caracterizado como o respeito pela vontade do sujeito e a necessidade de contar com o seu consentimento para experimento ou tratamento, está diretamente comprometido, uma vez que, não é dado esse direito ao sujeito ou seu responsável em decidir pelo procedimento, sendo esta uma determinação pronta e definida pelo Estado(7).

Além disso, o sucesso da vacinação depende ain$\mathrm{da}$ da necessidade de que as vacinas possuam alto padrão de segurança. Contudo, situaçóes como a presença de conservantes e coadjuvantes na sua composição, incluindo o timerosal, requerem ainda ampliação dos debates bioéticos sobre os seus efeitos no organismo dos vacinados(1).

O papel do Estado e os aspectos socioeconômicos da vacinaçáo

A utilização das vacinas começou como uma medida política-econômica e até hoje tem o Estado como seu maior incentivador que se utiliza de meios para obrigar a vacinação. O Estado realiza açôes de acordo com o que entende como o mais apropriado para a população, e esta recebe uma grande quantidade de informaçóes como uma quase coação. Ele diz como tem que modificar o seu próprio corpo a fim de se atingir um certo nível de segurança coletiva(11).
No entanto, o atual paradigma preventivo de vacinação em massa tem sido desafiado nas últimas décadas pela redução na incidência de doenças imunopreveníveis ficando extremamente raras, e até mesmo desconhecidas pela maioria da população, e com isso a atenção do público não está mais centrada nessas doenças, mas sim na segurança e eficácia das vacinas(1).

Sabe-se hoje que as vacinas são mais baratas para os países em desenvolvimento, que possuem condições sanitárias precárias e carência de recursos destinados às açóes de saúde pública, onde é melhor e mais barato vacinar e controlar uma doença porque o custo da cobertura vacinal fica menor do que o custo da doença $(1,2)$.

No entanto, onde o risco epidêmico da doença náo é mais elevado e o custo da cobertura fica mais alto, torna-se cada vez melhor trabalhar com a conscientização da população e controle sanitário para continuar sem a manifestaçáo da doença. Até porque, a inclusão da proteção do rebanho, faz com que aumente o número de casos evitados considerando que um percentual da população não vacinada está protegida pela vacinação da outra parcela (2-12).

Nessa reflexão, alguns autores questionam sobre se a continuação da vacinação em massa não está relacionada aos grandes interesses econômicos envolvidos na pesquisa, produção e distribuição de vacinas. Esse pensamento cria um ambiente de dúvida face aos saberes médicos e aos lucros das indústrias farmacêuticas(13).

A necessidade da vacinação em massa constitui no fundo um sinal indireto da ainda precariedade das infraestruturas sanitárias. Inclusive alguns estudos declaram, que retirava das vacinas a maioria dos benefícios que lhe haviam sido creditados no passado, pois atribuíam estas vantagens à melhora nutricional e às medidas de saneamento que passaram a ser adotadas como água potável, remoção de dejetos, segurança nos locais de trabalho etc (14).

Contudo, enquanto a maior parte da população brasileira não tiver melhor acesso aos bens culturais e aumento do seu nível educacional, as campanhas de vacinaçáo representarão a melhor pos- 
sibilidade de, em um curto período, realizar o que não se consegue em alguns anos sem a formação de uma consciência sanitária(15).

\section{Vacinação em massa e aspectos culturais}

No Brasil, campanhas empreendidas desde o final do século XX pelo Estado brasileiro, aponta para a existência de uma "cultura de imunização" estando esta associada a um processo de introdução de vacinas e de campanhas de vacinação em mas$\mathrm{sa}(13)$.

Atualmente não se observa uma coerção explícita do Estado no que se refere à vacinação, porém é necessário considerar que, os valores culturais não são respeitados frente a essa prática da vacinação em massa, justificando algumas condutas contrárias da população em relação à vacinação(16).

Assim, é necessário levar em consideração opiniôes e reflexóes de grupos que são contrários às vacinaçóes, bem como a exposição de seus argumentos e suas propostas. Essa recusa, muitas vezes está relacionada a indivíduos, grupos, família ou responsáveis, pertencentes a grupos influenciados por questôes filosóficas, religiosas, medo de eventos adversos ou por orientação médica(8).

Assim sendo, o grupo indígena atribui menor valor à prática da vacinaçáo enquanto resolução dos seus problemas de saúde e acreditam que a proteção proporcionada pela vacina, seja menor que a realização dos seus ritos tradicionais de proteção. Eles definem o processo de doença enquanto concepção coletiva, portanto consideram que a estratégia terapêutica também deve ser caracterizada por procedimentos coletivos, levando em consideração os seus rituais e crenças, a exemplo do xamanismo(17).

Um outro grupo que apresenta diversos aspectos culturais relacionados à recusa vacinal são os idosos. Entres as diversas crendices destaca-se a presença do medo, a questão dos eventos adversos e a crença do "idoso saudável". Desse modo, é necessário respeitar o ponto de vista dos idosos sobre a vacina, cabendo aos profissionais de saúde promover a informação, uma vez que, é essa falta de conhecimento que reforça as crendices e resulta na não vacinação (18).
É necessário considerar o direito do indivíduo na sua livre opção de escolha ou de recusa por um procedimento, este deve ser tratado com dignidade e ter garantido o acesso as informaçóes numa linguagem que seja compreensível(19).

O momento da vacinação deve ser proporcionado em um ambiente que respeite e valorize os aspectos culturais. Porém, observa-se muitas vezes que a aplicação de um imunobiológico ocorre sem o devido esclarecimento sobre os aspectos benéficos, eventos adversos e condutas que o vacinado deve adotar diante desses possíveis eventos(16).

Assim, é necessário promover uma reflexão sobre o processo histórico da vacinação que envolve poder, aspectos econômicos e éticos. Entendendo a necessidade de valorização das crenças, práticas culturais que envolvem um povo, onde estes têm suas influencias baseadas pela visão de mundo, linguagem, religião, contexto social, político, educacional, econômico, tecnológico e ambiental. Devendo, sobretudo a vacinação em massa promover um cuidado culturalmente competente e envolver o acesso a recursos culturalmente apropriados(16).

Este estudo tem como objetivo realizar uma discussão referentes à prática da vacinação em massa sob a ótica da bioética principialista considerado o papel do Estado e os aspectos culturais relacionados a essa prática.

\section{Metodologia}

Este trabalho é um estudo de revisão de literatura e para o levantamento bibliográfico foram utilizados busca em periódicos nacionais com recorte temporal de 1999 a 2013 nas bases de dados da Biblioteca Virtual em Saúde (BVS) - Literatura Latino-Americana e do Caribe em Ciências da Saúde (LILACS), Base de Dados da Enfermagem (BDENF), Scientific Electronic Library Online (SCIELO), MEDLINE.

Foram utilizados como descritores as palavras cadastradas no Medical Subject Headings - MeSH : Bioética, Vacinação em Massa, Características Culturais e Economia da Saúde, tendo sido encontrados 21 artigos relevantes para a abordagem do estudo. 


\section{Resultados e discussóes}

A partir da análise dos artigos selecionados, foi possível identificar que existe, de fato, uma efetividade relacionada ao processo de vacinação, sendo ratificada pela erradicação de doenças como, varíola, poliomielite e febre amarela, bem como, o controle de algumas outras doenças como o sarampo, tétano neonatal e tuberculose(3).

Mesmo reconhecendo a importância e a efetividade da vacinação, vale destacar que isso não a torna como pressuposto para desrespeitar a autonomia do indivíduo. Nesse sentido, entende-se que a corrente Principialista tem o papel de intermediar essas e outras situações contemporâneas, buscando náo determinar soluçóes definitivas dos problemas enfrentados e sim definir acordos pragmáticos, ou seja, acordos práticos e objetivos(7).

Assim como a vacinação, outras situações que também corroboram para a intervenção da bioética principialista são as técnicas de reprodução, de prolongamento da vida e os transplantes de órgãos. Essas novas demandas resultam na construção de um novo paradigma de resolução de conflitos éticos e morais(6).

Diz-se que a bioética trata, portanto, de questóes complexas que envolvem a vida e, por vezes, a morte, em situaçóes e contextos diversos, sendo considerada muitas vezes como um ponto de discussão e ponderação(10).

No que se refere a aplicabilidade da bioética principialista no contexto da vacinação em massa, tem-se que o princípio da autonomia é comprometido diante da obrigatoriedade do processo vacinal, considerando que o individuo náo é livre para tomar as suas decisões; em relação ao princípio da beneficência a vacinação busca a proteção contra as doenças específicas, porém temos que considerar os surgimentos dos eventos adversos, erros programáticos, a não avaliação do risco epidemiológico e a falta de informação oferecida pelos profissionais de saúde ligados ao processo de vacinação e o Estado para com o usuário, o que acaba comprometendo esse princípio.

Outro princípio da bioética que está sendo comprometido é o da não-maleficência que significa evitar qualquer tipo de risco, visto que, ainda hoje é bastante discutida a segurança dos produtos vacinais, além dos erros referentes aos processos de vacinação que são presentes e, por fim, o comprometimento do princípio da justiça o qual visa resolver questóes conflituosas relacionadas a vida coletiva, tendo a imposição do beneficio coletivo como argumento para as imposiçôes individuais.

Com isso, fica evidente que a ética não pode mais ser considerada apenas enquanto questáo de consciência, uma vez que, o seu conceito se ampliou e já engloba questóes como a análise das responsabilidades sanitárias e ambientais, sendo determinantes no auxilio da tomada de decisóes, na priorização das açôes e formação de pessoal(20).

Não se pode desvalorizar os aspectos culturais de vários grupos que muitas vezes vão de encontro a prática da vacinação. É necessário respeitar essas questóes, uma vez que, a garantia da autonomia e de sua história é um aspecto relevante enquanto princípio da bioética(8).

A cultura compreende reflexôes e variaçôes e é importante promover a sua valorização, no sentido de que a mesma não é caracteristicamente estática e que isso influencia nos hábitos de uma população. Considerando-se que ao promover a autonomia do individuo é facilitada a sua participação em seu processo de cuidado, se torna imprescindível considerar sua cultura, o que promoverá melhores resultados em saúde(21).

Nesta perspectiva, a política nacional de promoção da saúde vem confirmar também a importância de se promover a autonomia e a co-responsabilidade dos sujeitos, inclusive do poder público, no que se refere a saúde integral, respeitando as questóes culturais, envolvendo as desigualdades étnicas, racial, social, regional, de gênero, de orientação/opção sexual, entre outras(22).

Dentro desse contexto, é possível perceber que a educação sanitária e melhora da infraestrutura podem se caracterizar como uma alternativa para minimizar a prática compulsória da vacinação em massa e evitar novas disseminaçóes de doenças, garantindo a promoção da saúde(15). 
Aspectos bioéticos da vacinação em massa no Brasil - Andreia Souza de Jesus et al.

\section{Referencias}

1. Lessa SC, Dórea JG. Bioética e vacinação infantil em massa. Revista Bioética 2013; 21(2): 226-236.

2. Klepac P, Laxminarayan R, Grenfell BT. Sintetizando ótima epidemiológica e econômica para o controle de imunizar infecçôes. Procedings of the National Academy of Sciences 2011; 108(34): 14366-14370.

3. Ministério da saúde (BR), Secretaria de vigilância em Saúde, Departamento de vigilância Epidemiológica. Programa Nacional de Imunizaçōes 30 anos. Brasília: MS; 2003.

4. Ministério da Saúde (BR), Secretaria de vigilância em Saúde, Departamento de vigilância Epidemiológica. Programa Nacional de Imunizaçōes (PNI): 40 anos. Brasília: MS; 2013.

5. Bisetto LHL, Cubas MR, Malucelli A. A prática da enfermagem frente aos eventos adversos pós-vacinação. Revista Escola de Enfermagem da USP 2011; 45(5): 1128-1134.

6. Jucá RLC, Andrade DA. Da Bioética Principialista À Bioética Social: Estudo de Casos da Prática da Eutanásia no Brasil. In: Anais do XVIII Congresso Nacional do CONPEDI, 2009 Nov 04-07; São Paulo, Brasil. São Paulo: CONPEDI; 2009.

7. Soto, Luis G. Principialismo. Dicionário de Filosofia Moral e Politica. Equipe de

8. desenvolvimento Luis Abreu, João Brito, Ana Maia. Instituto de Filosofia da Linguagem 2002.

9. Levi GC. Recusa de vacinas: causas e consequências. São Paulo: Segmento Farma: 2013.

10. Brasil. Lei no 6.259, de 30 de outubro de 1975. Dispóe sobre a organização das ações de Vigilância Epidemiológica, sobre o Programa Nacional de Imunizaçóes, estabelece normas relativas à notificaçâo compulsória de doenças, e dá outras providências. Diário Oficial da República Federativa do Brasil, 30 de outubro de 1975.

11. Santos MFO, França GV. Bioética e Anestesia: Um Estudo Reflexivo de Publicações da Revista Brasileira de Anestesiologia. Rev. Bras de Anestesiologia. 2011; 61(1): 121-127.

12. Silva LJ. Vacinação, segurança de imunobiológicos e direitos do cidadão: Editorial. Revista Saúde Pública 1996; 30(4): 297-298.

13. Soarez PC, Sartori AMC, Santos A, Itria A, Novaes HM D, Martelli CMT. Contribuições da REVISÃO sistemática de Avaliações Econômicas: o Exemplo da Vacinação infantil contra Hepatite A no Brasil. Caderno de Saúde Pública 2012; 28(2).

14. Hochman G. Vacinação, varíola e uma cultura da imunização no Brasil. Revista Ciência e saúde coletiva 2011; 16(2): 375-386.

15. Moulin AM. A hipótese vacinal: por uma abordagem crítica e antropológica de um fenômeno histórico. Revista História, Ciências, Saúde 2003; 10 (suplemento 2): 499-517.

16. Garcia MRA, Lima E. Poder Público nas campanhas de Vacinação em Massa no Brasil. Revista Ciência, Cuidado e Saúde 2002; 1(1): 45-49.

17. Carvalho KM. A cultura de imunização no Brasil: reflexóes a partir da Teoria do Cuidado Transcultura. Revista de Enfermagem da UFPI 2012; 3(1): 226-229.

18. Garnelo L. Aspectos socioculturais da vacinação em área indígena. História, Ciências, Saúde - Manguinhos 2011; 18(1):175-190.

19. Gomes LM X, Antunes KR, Barbosa TLA, Silva CSO. Motivos que levaram os Idosos a não se vacinarem contra a Influenza Sazonal. Revista de pesquisa: Cuidado é fundamenta 2012; 4(3): 561-569.

20. Santos P, Espanhol A. Recusa Vacinal: o ponto de vista ético. Revista Portuguesa de Medicina Geral 2013; 29: 328-333.

21. Garrafa V. Da bioética de princípios a uma bioética interventiva. Bioética 2005;13(1): 125-134.

22. Lara MO, Brito, MJM, Resende LC. Aspectos culturais das práticas dos agentes comunitários de saúde em áreas rurais. Revista Escola de Enfermagem da USP 2012; 46(3): 673-680.

Recebido: 25 de julho de 2014

Aceito: 07 de outubro de 2014 